\title{
Paralytic Zebrafish Lacking Acetylcholine Receptors Fail to Localize Rapsyn Clusters to the Synapse
}

\author{
Fumihito Ono, ${ }^{1}$ Shin-ichi Higashijima, ${ }^{1,2,3}$ Anatoly Shcherbatko, ${ }^{1}$ Joseph R. Fetcho, ${ }^{1}$ and Paul Brehm ${ }^{1}$ \\ ${ }^{1}$ Department of Neurobiology and Behavior, State University of New York at Stony Brook, Stony Brook, New York 11794 , \\ 2 Precursory Research for Embryonic Science and Technology, Japan Science and Technology Corporation, Tokyo, Japan \\ 332-0012, and ${ }^{3}$ National Institute for Basic Biology, Okazaki, Japan 351-0198
}

Physiological analysis of two lines of paralytic mutant zebrafish, relaxed and sofa potato, reveals defects in distinct types of receptors in skeletal muscle. In sofa potato the paralysis results from failed synaptic transmission because of the absence of acetylcholine receptors, whereas relaxed mutants lack dihydropyridine receptor-mediated release of internal calcium in response to the muscle action potential. Synaptic structure and function appear normal in relaxed, showing that muscle paralysis per se does not impede proper synapse development. However, sofa potato mutants show incomplete development of the postsynaptic complex. Specifically, in the absence of ACh receptors, clusters of the receptor-aggregating protein rapsyn form in the extrasynaptic membrane but generally fail to localize to the subsynaptic region. Our results indicate that, although rapsyn molecules are capable of self-aggregation, interaction with $\mathrm{ACh}$ receptors is required for proper subsynaptic localization.

Key words: zebrafish; mutant; neuromuscular junction; acetylcholine receptor; dihydropyridine receptor; rapsyn; clustering
Studies using lines of mutant zebrafish have advanced our understanding of nervous system development significantly. In particular, many key components governing early differentiation have been identified. By contrast, few studies have used mutant zebrafish to identify key components involved in the physiological dysfunction of either nerve or muscle. Notable exceptions are studies on the paralytic mutant fish, nic, shown to result from a mutation in the $\alpha$ subunit of the muscle nicotinic receptor (Westerfield et al., 1990) and macho, a touch-insensitive mutant, shown to lack $\mathrm{Na}^{+}$channel function in the afferent sensory cells of the nervous system (Ribera and Nüsslein-Volhard, 1998). Surprisingly little attention has been paid to the mechanisms causal to locomotory dysfunction, given the large number of available mutant lines generated by ethylnitrosourea. These locomotory dysfunctional mutant lines exhibit behavioral manifestations ranging from uncoordinated swimming to total paralysis (Granato et al., 1996). To explore the physiological underpinnings of these locomotory problems, we initiated a hierarchical battery of morphological and physiological analyses. In particular, we used two lines of transgenic fish, one stably expressing green fluorescent protein (GFP) in motor neurons and the other stably expressing a rapsyn-GFP fusion protein in muscle, together enabling analysis of presynaptic and postsynaptic structures in vivo. This hierarchical approach provided for assignment of the

\footnotetext{
Received Feb. 22, 2001; revised May 8, 2001; accepted May 15, 2001.

This study was supported by National Institutes of Health Grants NS-18205 (P.B.) and NS-26539 (J.R.F.). We thank Dr. Frohnhoefer (Max Planck Institute) for providing sofa potato and relaxed mutant fish. Joan Speh offered expertise in immunohistochemistry and confocal microscopy. Shelagh Palma performed the genetic crosses, maintained the fish lines, and provided the embryos for analysis. We are grateful to Drs. Mandel and Matthews for help with molecular- and calciumimaging aspects of the project. The rapsyn-GFP fish was made when S.H. was in Dr. Ueno's lab at the National Institute for Basic Biology, Japan.

Correspondence should be addressed to Dr. Fumihito Ono, Department of Neurobiology and Behavior, State University of New York at Stony Brook, Stony Brook, NY 11794. E-mail: fono@notes.cc.sunysb.edu.

Copyright (C) 2001 Society for Neuroscience 0270-6474/01/215439-10\$15.00/0
}

dysf unction to the motor neuron, nerve-muscle synapse, or muscle proper. Our findings indicated two different and individually well characterized muscle receptor types as causal to the paralysis of sofa potato (sop) and relaxed (red) mutant lines. In the process of revealing the molecular mechanisms responsible for paralysis, we discovered, quite unexpectedly, a previously unidentified role for the acetylcholine receptor. Sofa potato mutant fish form membrane clusters of the receptor-associated protein rapsyn, but these clusters localize poorly to subsynaptic membrane because of the absence of the ACh receptor.

\section{MATERIALS AND METHODS}

Strains of fish. Mutant fish, sop ${ }^{\mathrm{t} 19 \mathrm{~d}}$ (sofa potato) and red ${ }^{\mathrm{t} 25 \mathrm{a}}$ (relaxed), were obtained from The Max Planck Institute (Tübingen, Germany) (Granato et al., 1996). After the cross of heterozygote parents, homozygous relaxed or sofa potato embryos were selected on the basis of an inability to move in response to touch. For some experiments sofa potato and relaxed fish were crossed with fish expressing GFP under control of the neural-specific Islet-1 promoter (Higashijima et al., 2000), and embryos that were heterozygous for the GFP transgene and homozygous for sop or red genes were tested. Another stable line of fish was developed that expressed a gene encoding a rapsyn-GFP fusion protein. To make the rapsyn-GFP construct, we amplified the mouse rapsyn coding sequence cDNA by PCR from embryonic mouse day 17 (E17) cDNA (Clontech, Palo Alto, CA). The primers used were 5', CTAGAATTCGCCACCATGGGGCAGGACCAGAC, and 3', TCTGGATCCACAAAGCCCGGCTT. The EcoRI and BamHI sites used in the cloning are underlined. The 5'-primer also included a Kozak consensus sequence for initiation of the translation. The amplified rapsyn cDNA was subcloned into pEGFP-N1 (Clontech). To make the final plasmid construct for the $\alpha$-actin/rapsyn-GFP transgene fish, we subcloned, in this order, the zebrafish $\alpha$-actin promoter sequence (Higashijima et al., 1997), the rapsynGFP cDNA, and bovine growth hormone poly(A) signal, derived from pcDNA3 (Invitrogen, Carlsbad, CA), in the pBluescript SK vector (Stratagene, La Jolla, CA). Generation of transgenic fish was performed as reported previously (Higashijima et al., 1997). One of 10 fish produced fluorescent embryos.

Imaging of neurons and neuromuscular junctions. For in vivo imaging, fluorescent embryos were anesthetized first in $10 \%$ Hank's solution with $0.02 \%$ MS222 (Fetcho and O'Malley, 1995), embedded in 1\% agarose, 
and mounted on a coverslip. The nerve and muscle were visualized through the transparent skin with an inverted Zeiss 510 confocal laserscanning microscope (Oberkochen, Germany). To label the ACh receptors in GFP-expressing lines, we peeled the skin from the opposite side of the fish to allow for access of rhodamine-conjugated $\alpha$-bungarotoxin (Molecular Probes, Eugene, OR). The fish were kept in $100 \%$ Hank's solution containing $10^{-7} \mathrm{M}$ toxin for $15 \mathrm{~min}$. Then the fish were washed for $2 \mathrm{hr}$ in toxin-free Hank's solution to remove nonspecific binding of the toxin.

Immunohistochemical labeling was performed on 5-d-old fish that were fixed with $4 \%$ paraformaldehyde at $4{ }^{\circ} \mathrm{C}$. The fish were washed with distilled water for $5 \mathrm{~min}$, treated with acetone for $7 \mathrm{~min}$ at $-20^{\circ} \mathrm{C}$, and thoroughly washed again with water. After incubation in PBS (Life Technologies, Grand Island, NY) containing 2\% horse serum and $0.5 \%$ Triton X-100, the fish were treated with the primary antibody (mAb35; 1:3000; Research Biochemicals, Natick, MA). After thorough washing, the fish were incubated with an FITC-conjugated donkey anti-rat IgG secondary antibody (1:100). The fish were washed for an additional $2 \mathrm{hr}$ before testing.

To view synaptic terminals in the rapsyn-GFP line of fish, we anterogradely labeled motor neurons with Texas Red-dextran (Molecular Probes). For this purpose, injection electrodes with a tip diameter of $\sim 15$ $\mu \mathrm{m}$ were filled with a solution containing $50 \mathrm{mg} / \mathrm{ml}$ dye. The tip of the electrode was inserted into the spinal cord. Within seconds the dye diffused out the tip, and the electrode was withdrawn immediately. Within 15 min after injection the fluorescence was observed to label the motor neurons and their associated terminals.

Colocalization of Texas Red-labeled terminals and rapsyn-GFP was quantitated by off-line analysis of confocal images. The fractional area of red-positive pixels in a $1024 \times 1024$ unprocessed image that also scored positive for green was used to compute the coefficient of colocalization for each field. Green-positive pixels lacking associated red-positive pixels are expected to occur, because some nerve terminals were not labeled in the injection process. The myosepta regions were excluded from analysis because this area represents the largest tract of axons of the motor neurons. Multiple fields were counted in each fish; typically, a single field comprised approximately one-half of a body segment. The detection threshold for scoring a pixel as either green- or red-positive was set to the midpoint of the full range of intensities for that color, measured for each image.

For measurement of GFP fluorescence of motor neurons and rapsynGFP, excitation was $488 \mathrm{~nm}$ and emission was bandpass-filtered between 505 and $530 \mathrm{~nm}$. The fluorescence associated with both Texas Red and rhodamine was viewed by using $543 \mathrm{~nm}$ excitation and $560 \mathrm{~nm}$ long-pass emission filter. FITC immunohistochemical labeling of ACh receptors used $488 \mathrm{~nm}$ excitation and 505-550 $\mathrm{nm}$ emission filter.

Measurements from dissociated myocytes. To obtain individual muscle cells, we decapitated anesthetized fish between the ages of 3 and $5 \mathrm{~d}$ and cut them into several pieces. The pieces were treated with $1 \%$ collagenase for $1 \mathrm{hr}$ and triturated; the dissociated muscle cells were plated on either plastic dishes or poly-L-lysine-treated glass coverslips. Then the coverslips were flooded with the culture medium containing $60 \%$ L-15 (Life Technologies), $10 \mathrm{~mm}$ HEPES, $100 \mathrm{U} / \mathrm{ml}$ penicillin/streptomycin, and $0.5 \%$ horse serum. Adherent phase-bright myocytes were used on the same day or the day after dissociation.

To stain for T-tubules, we soaked dissociated myocytes from wild-type and relaxed mutant fish in solution containing $5 \mu \mathrm{M}$ of Di-8-ANEPPS (Molecular Probes) for $2 \mathrm{~min}$ and then washed and viewed them with a Plan Apochromatic $100 \times$ objective (numerical aperture, 1.4), using 488 $\mathrm{nm}$ excitation and $560 \mathrm{~nm}$ long-pass filter. To disrupt T-tubules, we treated the myocytes with $2 \mathrm{M}$ formamide for $15 \mathrm{~min}$, followed by a 40 min wash. Finally, the myocytes were labeled with Di-8-ANEPPS as described above.

Intracellular calcium responses to caffeine were measured in dissociated muscle from both wild-type or relaxed mutants. Dissociated myocytes from day 3 fish were soaked in an extracellular solution containing $5 \mu \mathrm{M}$ fura-2 AM for $15 \mathrm{~min}$ and washed in a fura-free solution for an additional $15 \mathrm{~min}$. The extracellular solution contained (in mM) 100 $\mathrm{NaCl}, 2 \mathrm{KCl}, 2 \mathrm{CaCl}_{2}, 1 \mathrm{MgCl}_{2}, 5 \mathrm{HEPES}$, and 3 glucose, $\mathrm{pH}$ 7.4. The method for photometric calcium measurement was similar to that described previously (Heidelberger and Matthews, 1992). A stable baseline fluorescence signal was established by using excitation wavelengths of 360 and $390 \mathrm{~nm}$ with a photo multiplier tube. Calcium transients were measured in response to puffer application of either a high $\mathrm{K}^{+}$or caffeine solution. For caffeine application, $3 \mathrm{~mm}$ caffeine was diluted into the extracellular solution. The high potassium solution contained (in $\mathrm{mM}$ ) 50 $\mathrm{NaCl}, 52 \mathrm{KCl}, 2 \mathrm{CaCl}_{2}, 1 \mathrm{MgCl}_{2}, 5 \mathrm{HEPES}$, and 3 glucose, $\mathrm{pH}$ 7.4. Signals were obtained with X-chart in Macintosh, and the ratio of emissions at 360 and $390 \mathrm{~nm}$ excitations was calculated.

Electrophysiology of dissociated cells. Patch-clamp recordings of myocytes were made by the whole-cell ruptured technique. Patch pipettes were pulled to an outer diameter of $2-3 \mu \mathrm{m}$ and fire-polished immediately before use. The electrode resistance corresponded to 3-5 $\mathrm{M} \Omega$, and the access resistance after rupture was 10-20 M $\Omega$. The pipette solution used for current-clamp recording of the myocyte action potential and voltage-clamp recording of ACh-activated current contained (in mM) 120 $\mathrm{KCl}, 5 \mathrm{BAPTA}$, and 5 HEPES, $\mathrm{pH}$ 7.1. For voltage-clamp recording of $\mathrm{Na}^{+}$current the pipette solution contained (in mM) $58 \mathrm{CsCH}_{3} \mathrm{SO}_{3}, 32$ $\mathrm{CsCl}, 10 \mathrm{EGTA}$, and $10 \mathrm{HEPES}, \mathrm{pH}$ 7.1. The extracellular solution for both current- and voltage-clamp recordings contained (in $\mathrm{mM}$ ) $100 \mathrm{NaCl}$, $2 \mathrm{KCl}, 0.2 \mathrm{CaCl}_{2}, 2.8 \mathrm{MgCl}_{2}, 3$ glucose, and 5 HEPES, pH 7.4. Membrane currents were recorded with an EPC-9 amplifier (List Electronics, Darmstadt-Eberstad, Germany). The currents were sampled at $50 \mathrm{kHz}$ and filtered at $3-5 \mathrm{kHz}$ before analysis. Capacitive transients were compensated by using a combination of manual compensation on the amplifier and a P/10 protocol. Data were analyzed with Pulsefit (HEKA, Lambrecht, Germany) and IgorPro (WaveMetrics, Lake Oswego, OR) software.

For the recording of dihydropyridine (DHP) charge movement in myocytes, a prepulse protocol similar to that described by Adams et al. (1990) was used with some modifications. The command voltage was stepped from a holding potential of -90 to $-30 \mathrm{mV}$ for $250 \mathrm{msec}$, then to $-50 \mathrm{mV}$ for $5 \mathrm{msec}$, then to the test potential for $20 \mathrm{msec}$, and finally back to $-90 \mathrm{mV}$. The pipette solution contained (in mM) $130 \mathrm{Cs}-$ aspartate, $5 \mathrm{MgCl}_{2}, 10$ EGTA, and 10 HEPES, $\mathrm{pH}$ 7.1. External solution contained (in mM) 130 TEA-Cl, $10 \mathrm{CaCl}_{2}, 1 \mathrm{MgCl}_{2}, 10 \mathrm{HEPES}, 0.5$ $\mathrm{CdCl}_{2}$, and $0.1 \mathrm{LaCl}_{3}, \mathrm{pH}$ 7.4.

In vivo recording of synaptic currents. Embryos at days 6 or 7 were fixed with tungsten pins to a $35 \mathrm{~mm}$ plastic dish coated with Sylgard (Dow Corning, Midland, MI) and placed under a stereo microscope. The dish was flooded with a recording solution containing (in $\mathrm{mM}$ ) $105 \mathrm{NaCl}, 4$ $\mathrm{CaCl}_{2}, 1 \mathrm{MgCl}_{2}, 2 \mathrm{KCl}, 5 \mathrm{HEPES}$, and 3 glucose, $\mathrm{pH}$ 7.4. For mutants, only embryos with vigorous heartbeat were used for the experiment. The skin was peeled from one side of the fish with tungsten needles and forceps to allow access to muscle. The recording techniques were similar to those used for dissociated myocytes. The pipette solution contained (in mM) $120 \mathrm{KCl}, 5 \mathrm{HEPES}$, and 5 BAPTA, pH 7.1. To stimulate the spinal cord, we pressed etched platinum wire electrodes on the body surface from above and below the fish at the level of spinal cord. With the exception of the fine tip, each electrode was insulated along the entire length with a coating of glass. Attempts were made to locate the stimulating and recording electrodes in the same segments of the tail. Spinal neurons were stimulated with a Grass Instruments (West Warwick, RI) model SD5 stimulator, and the stimulus strength was adjusted to the lowest voltage that consistently would evoke synaptic responses in muscle. With short pulse durations of $60-100 \mu \mathrm{sec}$, the stimulus amplitude generally corresponded to 5-20 V.

\section{RESULTS}

\section{Sofa potato mutant fish lack acetylcholine receptors}

Homozygous sofa potato mutants were identified by their inability to swim when prodded mechanically. Direct depolarization of dissociated myotomal muscle, via either fast application of a high $\mathrm{K}^{+}$solution or electrical stimulation, resulted in muscle contractures that were similar to those of wild-type fish. These results indicated that the dysfunction is likely to reside upstream of excitation-contraction coupling in this mutant line.

To investigate upstream signaling, we excited spinal motor neurons by extracellular stimulation of the spinal cord. In wildtype embryos, increasing stimulus strength resulted in visible contractions of segmental muscle. However, stimulation of sofa potato embryos resulted in no visible contractions at similar stimulus intensity, consistent with the idea that the defect was in either motor neuron excitability or neuromuscular transmission. Synaptic function was tested directly by means of patch-clamp recording of myotomal muscle in intact, restrained fish. In wild- 


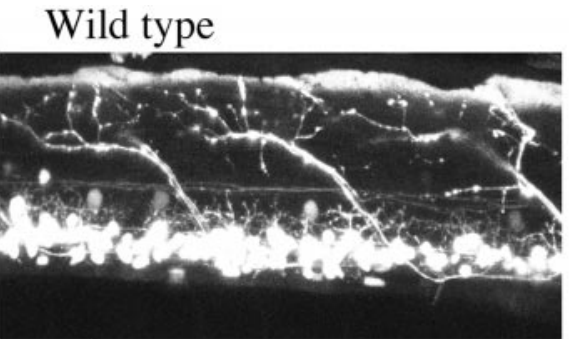

sofa potato

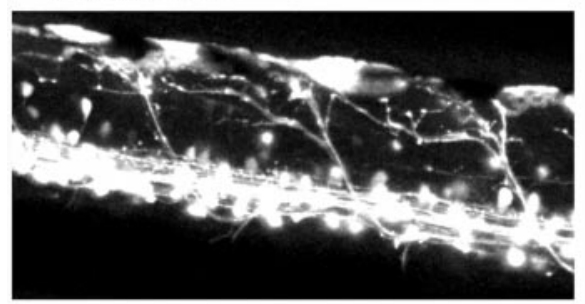

relaxed
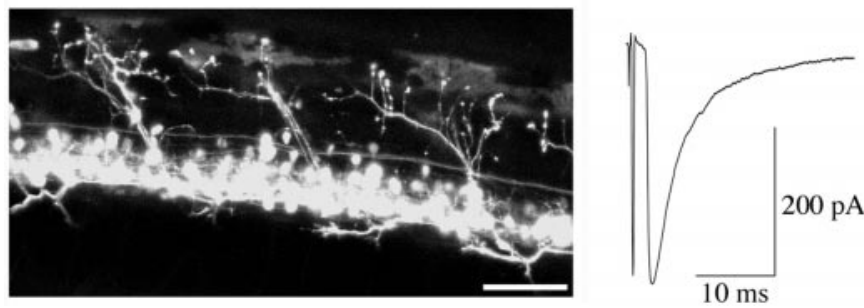

Figure 1. Expression of cytoplasmic GFP in motor neurons of wild-type and mutant fish. Left, The somas and axons of secondary motor neurons expressing the GFP are visualized (see Materials and Methods). The stacked images were obtained from intact fish because of the transparency of the skin. The skin exhibits autofluorescence that can be detected along the top edge of the body. The wild-type and both mutant fish were $5 \mathrm{~d}$ old. Scale bar, $50 \mu \mathrm{m}$. Right, Electrophysiological recordings of evoked synaptic currents from voltage-clamped muscle cells after extracellular stimulations of spinal cord (see Materials and Methods). The stimulus artifact precedes the synaptic response in muscle. Note the lack of response in sofa potato muscle.

type fish both spontaneous and stimulus-evoked synaptic currents could be recorded (Fig. 1). Both forms of synaptic response were blocked after the addition of $10^{-7} \mathrm{M} \alpha$-bungarotoxin ( $\alpha$-Btx). By contrast, recordings from muscle of sofa potato fish indicated no signs of either spontaneous or evoked synaptic currents (Fig. 1).

To determine whether synaptic failure originated from presynaptic or postsynaptic dysfunction, we tested the ability of muscle to respond to direct application of $\mathrm{ACh}$. For this purpose we dissociated individual muscle cells from wild-type and sofa potato mutant fish and measured inward current responses to applied ACh (Fig. 2). In all eight wild-type muscle cells that were tested at $-90 \mathrm{mV}$, large responses to puffer-applied $10 \mu \mathrm{M}$ ACh were observed. By contrast, all sofa potato muscle cells that were tested failed to show inward current responses to applied ACh. These results pointed to an absence of functional ACh receptors as causal to the paralysis.

To determine whether postsynaptic ACh receptors were present but not functional, we labeled intact fish with rhodamineconjugated $\alpha$-Btx (Rh- $\alpha$-Btx; Fig. 2). Muscle from wild-type fish exhibited intense staining at both the ends of the muscle cells and at discrete sites within the muscle cells. However, no labeling was observed in muscle from sofa potato. Even after dissociation, careful scrutiny of the muscle surface revealed no evidence of
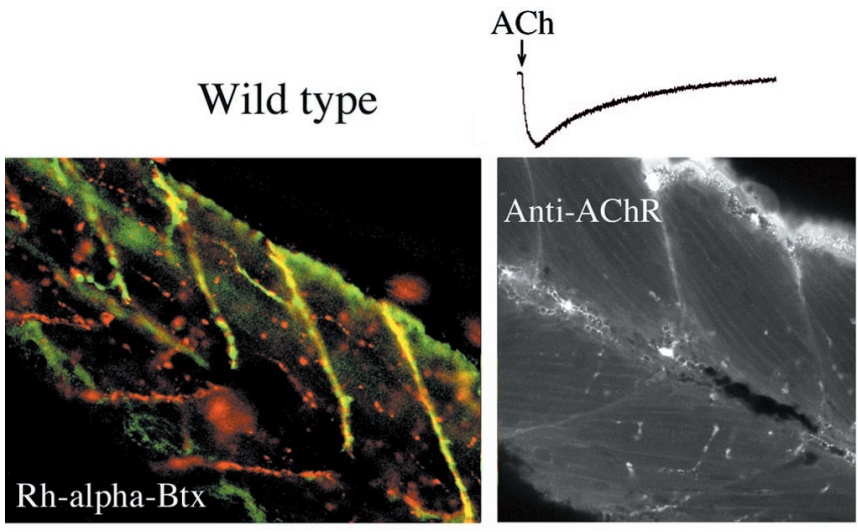

sofa potato
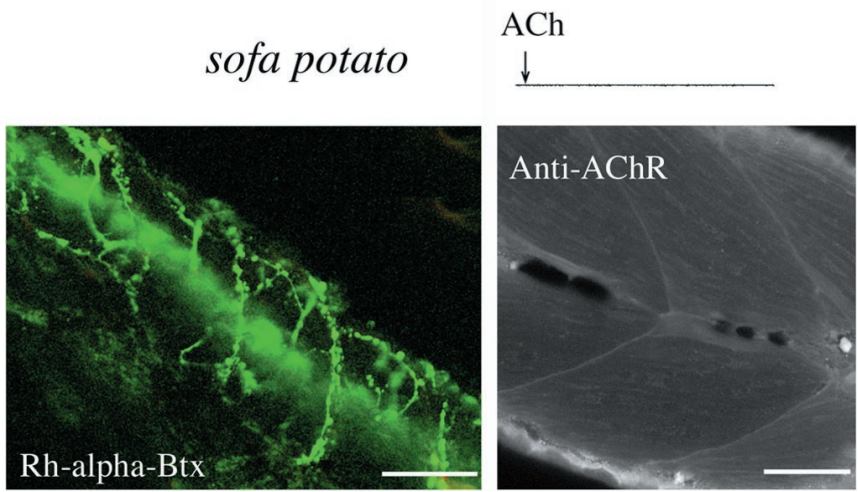

Figure 2. Labeling of ACh receptors by $\alpha$-bungarotoxin and immunohistochemistry. Shown is the response of muscle cells from 5-d-old wildtype (top trace) and sofa potato (bottom trace) fish to transiently applied 10 $\mu \mathrm{M}$ ACh. Note the lack of response by sofa potato muscle. Muscle from wild-type/Isl1-GFP (top) and sofa potato/Isl1-GFP (bottom) lines was treated with rhodamine- $\alpha$-bungarotoxin. In the top panel the red fluorescence in wild-type muscle corresponds to the location of ACh receptors. The green fluorescence from the cytoplasmic GFP indicates the location of axons and synaptic terminals. The plane of focus was set at a different level from the spinal cord so that the somata of motor neurons are not seen. In sofa potato fish (bottom) the green fluorescence resulting from GFP is observed, but no red fluorescence corresponding to rhodamine$\alpha$-Btx is observed. The right panels show black and white images of mAb35 labeling of $\mathrm{ACh}$ receptors in fixed muscle from 5-d-old fish. Some autofluorescence from the skin is seen along the edge of the tail. Fluorescence that is associated with the labeling of $\mathrm{ACh}$ receptors is absent in sofa potato muscle. Scale bars, $50 \mu \mathrm{m}$.

labeling by $\alpha$-Btx in these mutant fish. As further evidence that the receptors were absent, we labeled muscle by using the mAb35 monoclonal antibody which is directed against epitopes on the $\alpha$ subunit of the receptor that are different from the $\alpha$-Btx binding. In muscle from wild-type fish, mAb35 labeling revealed a receptor distribution consistent with the findings based on an $\alpha$-Btx staining site (Fig. 2, Anti-AChR; Saedi et al., 1990). However, in sofa potato fish the mAb35 failed to exhibit any specific labeling, as was observed for $\alpha$-Btx staining. Thus, the collective results from Btx and mAb35 labeling indicate that $\mathrm{ACh}$ receptors are absent in muscle from sofa potato fish.

To determine whether the paralysis hindered differentiation of the innervating motor neurons, we crossed sofa potato fish with wild-type fish stably expressing GFP in the nervous system (Higashijima et al., 2000). The expression of GFP in the parental transgenic line was restricted, primarily to the cranial motor neurons and secondary motor neurons in the trunk (Fig. 1). The motor neurons projecting to ventral muscle, however, were not well labeled, so we restricted our analysis to dorsal muscle. The 
Figure 3. Relaxed mutant fish show functional defects in DHP receptors. A, Top traces, Voltage records from a dissociated myocyte from relaxed fish showing responses to current injection. One trace shows a subthreshold passive response, and a second trace shows a muscle action potential when the stimulus strength was increased. The dashed line denotes $0 \mathrm{mV}$. Bottom traces, Inward $\mathrm{Na}^{+}$currents in response to 10 msec test pulses from muscle cells of relaxed mutant fish. The potential was stepped from $-90 \mathrm{mV}$ in $10 \mathrm{mV}$ increments to test potentials ranging from -50 to $+10 \mathrm{mV}$. $B$, Photometric measurements of intracellular calcium levels in wild-type and relaxed myocytes. Shown are the changes in ratio of fura- 2 AM fluorescence measured at 360 and $390 \mathrm{~nm}$ wavelength excitation. The wild-type muscle responses to pufferapplied $52 \mathrm{mM} \mathrm{K}^{+}$solution and $3 \mathrm{~mm}$ caffeine solution are indicated by the arrows. Muscle from relaxed mutant fish responded to caffeine but failed to respond to high $\mathrm{K}^{+}$solution. $C$, Dissociated myotubes from wild-type and relaxed mutants stained with Di-8-ANNEPS show the distribution of z-bands. Disruption of wild-type T-tubules by treatment with $2 \mathrm{M}$ formamide led to a disappearance of the fluorescence labeling by the dye. Scale bar, $5 \mu \mathrm{m}$. $D$, Whole-cell recordings of charge displacement in myocytes from wild-type and relaxed fish are shown. Traces from muscle cells of similar sizes, capacitance, and age $(3 \mathrm{~d}$ old $)$ are shown for wild-type and mutant fish. The responses to the test potentials are indicated. The voltage protocols and solutions that were used to eliminate ionic and capacitive currents are indicated in Materials and Methods. In the associated plot the charge movement integrals $\left(Q_{\text {on }}\right)$ for wildtype (filled circles) and relaxed (filled triangles) fish are plotted against test potential voltages. The mean values and SDs for seven muscle cells are shown. The data are fit according to: $Q_{\mathrm{on}}=$ $Q_{\max } /\left\{1+\exp \left[-\left(V-V_{1 / 2 \mathrm{O}}\right) / k_{\mathrm{O}}\right]\right\}$, where $Q_{\max }$ is the maximum charge, $V_{1 / 2 \mathrm{Q}}$ is the voltage at which one-half of the charge has moved, and $k_{\mathrm{Q}}$ is a slope factor. For the fitted curve of wild-type $Q_{\text {on }}$ shown in the graph, $Q_{\max }=10.8$, $V_{1 / 2 \mathrm{Q}}=-9.85$, and $k_{\mathrm{Q}}=11.1$.
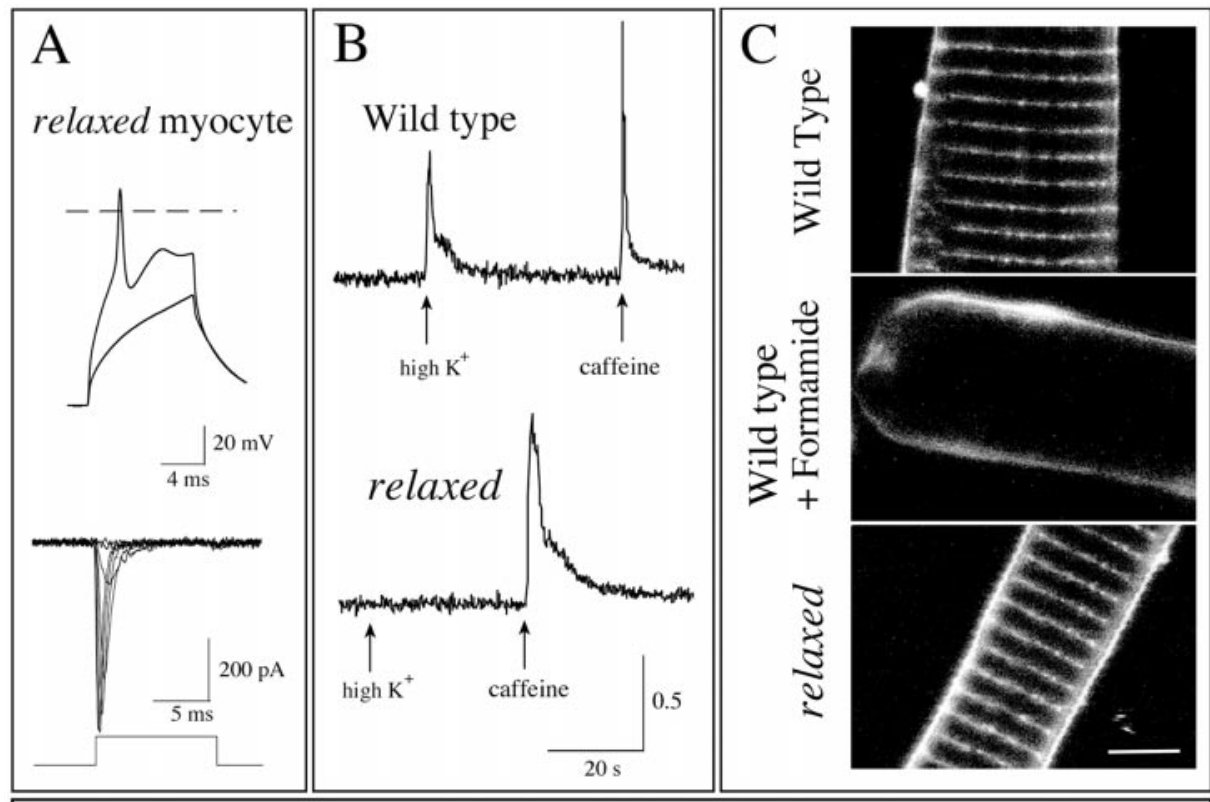

D

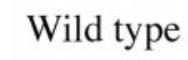

relaxed

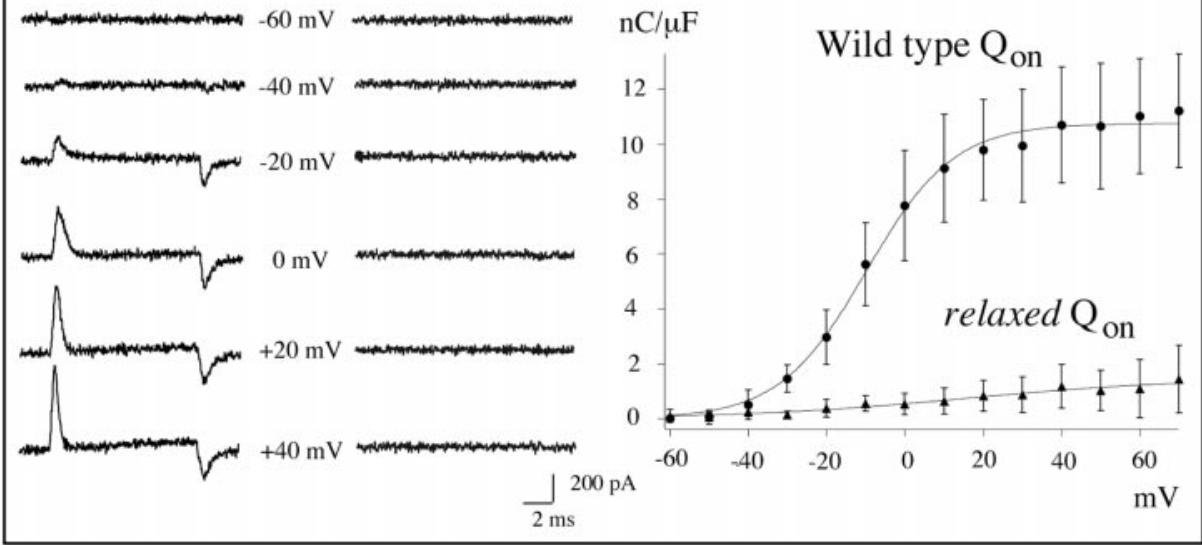

labeling in these neurons was so intense that it was possible to resolve the projections as well as the individual terminals in both sofa potato and wild-type fish. In sofa potato fish, lacking ACh receptors and synaptic transmission, it appears that the motor neurons are still capable of forming terminal-like endings on the myotomal muscle (Fig. 1).

\section{Relaxed mutant lacks proper excitation-contraction coupling}

Unlike sofa potato fish, homozygous relaxed mutants were unable to contract their myotomal tail muscle in response to direct extracellular electrical stimulation. Additionally, depolarization of dissociated tail muscle from relaxed mutants showed no ability to contract in response to the rapid application of high $\mathrm{K}^{+}$ solution. These results indicated that the defect in relaxed resided downstream of synaptic transmission, in the muscle proper. Therefore, our starting point for physiological analyses of this mutant line was analysis of muscle function.

Whole-cell patch-clamp measurements from relaxed myotomal muscle indicated that excitability was intact (Fig. 3A). First, current-clamp recordings from dissociated muscle revealed $\mathrm{Na}^{+}$based action potentials at depolarization that were similar to wild-type muscle cells (Fig. 3A). Second, whole-cell voltageclamp recordings from relaxed muscle revealed robust voltagedependent $\mathrm{Na}^{+}$currents that were similar, in both voltage dependence and kinetics, to those in wild-type muscle (Fig. 3A). The finding that relaxed muscle can generate action potentials pointed to a dysfunction further downstream than membrane excitation mechanisms.

A defect in contractile machinery proper could be excluded by experiments in which caffeine was applied directly to dissociated muscle. When $3 \mathrm{~mm}$ caffeine was puffed on either muscle from relaxed or wild-type fish, contractions ensued. Caffeine is known to cause the direct release of internal calcium via activation of the ryanodine receptor, the physiological trigger for a normal release of calcium. To establish further that these contractions were a consequence of calcium release, we loaded muscle from relaxed and wild-type fish with a fura- 2 AM calcium indicator. Photometric measurements of internal calcium levels with the fura-2 AM indicator were used to follow calcium concentration changes in muscle (Fig. 3B). Application of either high $\mathrm{K}^{+}$solution or a solution containing $3 \mathrm{~mm}$ caffeine led to transient and large increases in internal calcium in wild-type muscle. By contrast, 
high $\mathrm{K}^{+}$solution did not alter internal calcium levels in muscle from relaxed mutants. However, as in wild-type muscle, $3 \mathrm{~mm}$ caffeine elicited calcium responses in relaxed muscle. These findings circumscribed a radius of dysfunction in relaxed residing somewhere between the muscle action potential and the release of internal calcium.

Coupling between the muscle action potential and intracellular calcium release requires that the action potential propagate into the T-tubular system and subsequently activate DHP receptors via depolarization. We first explored the possibility that T-tubules may be disrupted physically in the muscle of relaxed, thereby interrupting the propagation of the action potential. For this purpose, individual dissociated muscle cells were stained with a membrane-selective dye Di-8-ANEPPS, a dye that specifically labels plasma membrane and T-tubular membrane (Huser et al., 1996; Lipp et al., 1996). In dissociated muscle from wild-type fish, clear labeling of the z-band regions by the dye was observed (Fig. $3 C$ ). In muscle cells pretreated with formamide to break the connection between the T-tubules and the muscle plasma membrane, no staining of z-bands was observed. Labeling of relaxed mutant muscle by Di-8-ANEPPS was similar to that obtained for wild-type muscle, indicating that the disruption of T-tubules was not causal to paralysis.

Dysfunction at the level of DHP receptors was examined by recording the DHP gating charge movements elicited by muscle membrane depolarization. In mammalian muscle the proper functioning of this population of voltage-sensing receptors is reflected in the large charge movements recorded at their simultaneous activation (Melzer et al., 1995). To observe charge movements of the DHP receptors, we first blocked all active conductances in the muscle cells. Ionic currents were blocked by the use of an external solution containing low concentrations of $\mathrm{Na}^{+}$ along with the calcium channel blockers $\mathrm{Cd}^{2+}$ and $\mathrm{La}^{3+}$. Outward $\mathrm{K}^{+}$current was blocked by the inclusion of $\mathrm{Cs}^{+}$in the pipette. The charge movements associated with the $\mathrm{Na}^{+}$channel activation were attenuated by the use of a conditioning depolarization that inactivated the channels. Muscle membrane capacitive currents were compensated, and residual currents were subtracted from the records by means of $\mathrm{P} / 10$ protocols. The residual current observed during test pulse depolarizations reflects the DHP gating charge (Adams et al., 1990). This method resulted in currents that could be recorded on depolarization, which were ascribed to charge movements of the DHP receptor (Fig. 3D). In wild-type muscle we recorded asymmetrical on- and off-gating currents over a range of potentials. When the integrals of ongating charge movement were calculated and plotted against membrane voltage, the plots were fit well with the Boltzmann equation (Fig. 3D). The parameters gained from fitting were close to those observed in intramembrane charge movement in mouse (Adams et al., 1990). In contrast to the robust on- and off-gating charge movements in wild-type muscle, recordings from paralytic muscle revealed severely reduced charge movements. In three muscle cells that were tested from relaxed we were unable to record any gating charge movements. We therefore suspect dysfunctional DHP receptors as the culprit protein, rendering excitation-contraction coupling in relaxed muscle ineffective.

As with sofa potato we crossed the motor neuron-GFP line with relaxed to generate paralytic fish with fluorescent motor neurons. Comparisons of the overall morphology of the GFPlabeled motor neurons in relaxed showed no obvious difference from wild type (Fig. 1). Furthermore, recordings of synaptic currents from voltage-clamped muscle cells in relaxed indicated that
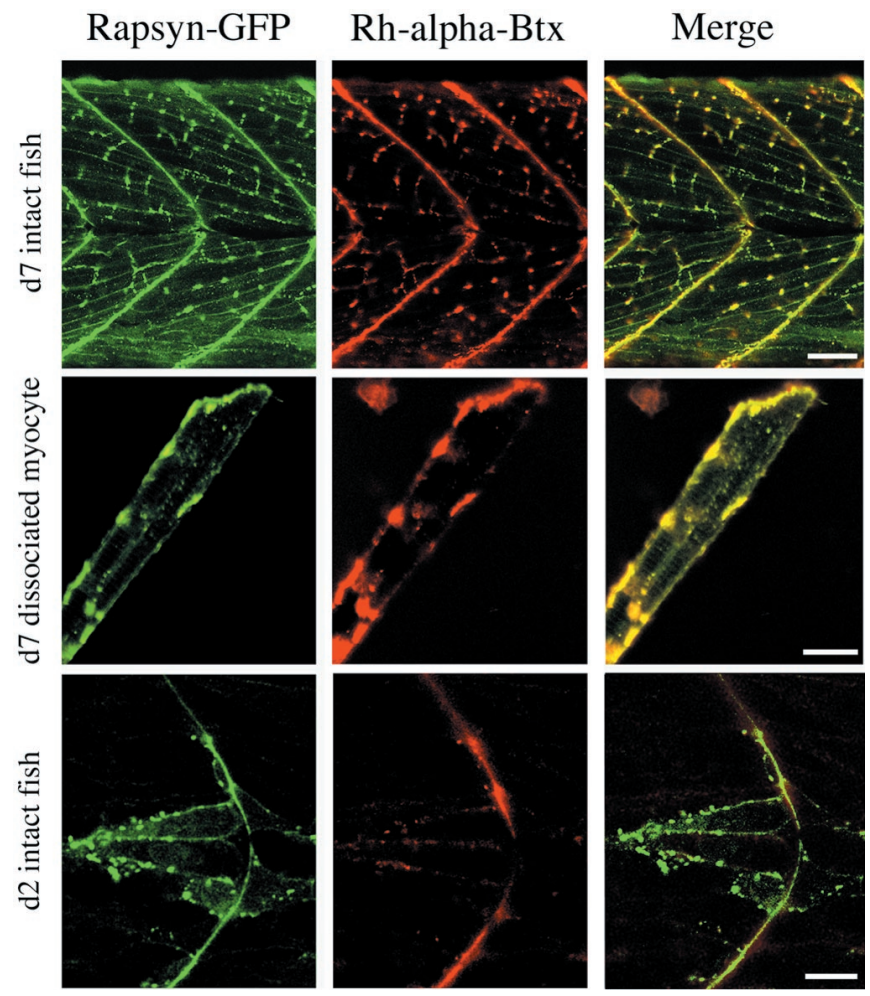

Figure 4. Developmental changes in the relationship between ACh receptor and rapsyn-GFP distribution. Left, Rapsyn-GFP distribution in the tail muscle of an intact 7-d-old wild-type/rapsyn-GFP fish (top), dissociated wild-type/rapsyn-GFP myocyte (middle), and 2-d-old wildtype/rapsyn-GFP fish (bottom). The green fluorescence indicates the distribution of rapsyn-GFP. Middle, The distribution of fluorescence associated with the labeling of ACh receptors by rhodamine- $\alpha$-Btx in the same muscle shown at the left. Right, The green fluorescence associated with the rapsyn-GFP fusion protein and the red fluorescence from the rhodamine- $\alpha$-Btx-labeled ACh receptors are merged for the left and middle images. Scale bars: Top, $50 \mu \mathrm{m}$; middle, $20 \mu \mathrm{m}$; bottom, $10 \mu \mathrm{m}$.

synaptic function is unaffected by the mutation (Fig. 1). Thus, muscle paralysis has no obvious deleterious effects on either the motor neuron morphology or neuromuscular transmission.

\section{Postsynaptic organization is disrupted in sofa potato}

The specific absence of $\mathrm{ACh}$ receptors at neuromuscular junctions in sofa potato embryos raised the question of the distribution and function of $\mathrm{ACh}$ receptor-associated proteins. Intimately associated with $\mathrm{ACh}$ receptors at the synapses are rapsyn molecules, which are responsible for clustering of the receptors (Froehner et al., 1990; Apel et al., 1995; Gautam et al., 1995). To visualize the distribution of rapsyn molecules in living fish, we first generated a stable line of fish expressing a rapsyn-GFP fusion protein. The GFP was fused to the C-terminal end of the mouse rapsyn protein. The expression of this fusion protein was under the control of a muscle-specific actin promoter (Higashijima et al., 1997); therefore, the rapsyn-GFP was transcribed and expressed in skeletal muscle from very early developmental stages. We crossed sofa potato with fish expressing rapsyn-GFP and compared the distribution of rapsyn-GFP in wild-type and sofa potato background, designated as wild-type/rapsyn-GFP and sofa potato/rapsyn-GFP.

In 7-d-old wild-type/rapsyn-GFP fish the majority of rapsynassociated fluorescence was clustered in the myotomal muscle (Fig. 4). Colabeling with Rh- $\alpha$-Btx indicated a close correspon- 


\section{sofa potato/rapsyn-GFP fish}

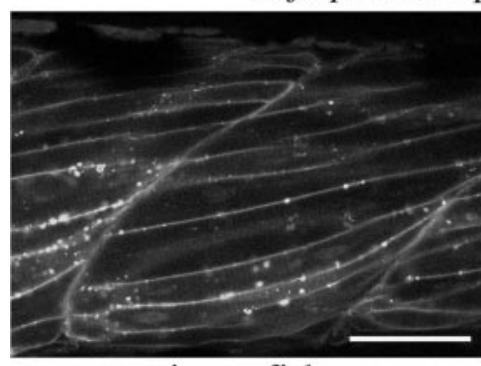

intact fish

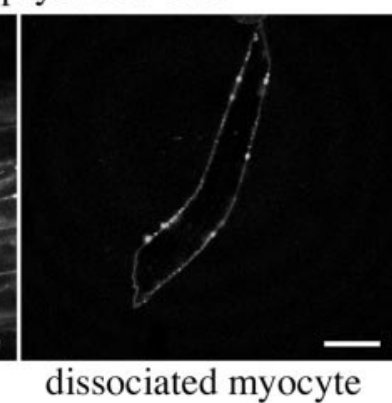

Figure 5. The distribution of rapsyn-GFP fluorescence in 5-d-old sofa potato mutant fish. The distribution of rapsyn-GFP in intact tail muscle (left) and in a dissociated myocyte (right) is shown also. Scale bars: Left, $50 \mu \mathrm{m} ;$ right, $20 \mu \mathrm{m}$.

dence between the distribution of rapsyn and $\mathrm{ACh}$ receptor clusters (Fig. 4). All clusters of ACh receptors were colocalized with rapsyn-GFP. However, slight evidence of unclustered rapsyn could be observed as a thin layer of diff use labeling in the membrane of muscle cells, and this rapsyn appeared sometimes to lack associated $\mathrm{Rh}-\alpha$-Btx label. Such a close correspondence between clustered rapsyn and $\mathrm{ACh}$ receptor was not seen in 2-d-old fish (Fig. 4). At these earlier stages of development, muscle pioneer cells (Currie and Ingham, 1996) expressed rapsyn clusters that lacked associated Rh- $\alpha$-Btx label, whereas the clustered Rh- $\alpha$-Btx label invariably was associated with the rapsynGFP label. The receptorless clusters of rapsyn-GFP in these muscle pioneer cells likely reflect the very early stages of neuromuscular synapse development.

To establish further the interdependence between ACh receptors and rapsyn, we examined the sofa potato/rapsyn-GFP fish. In these embryos, muscle labeling by rapsyn-GFP was observed despite the lack of $\mathrm{ACh}$ receptors (Fig. 5). The distribution of rapsyn-GFP in intact and dissociated muscle from sofa potato was qualitatively similar to that observed for wild type. Specifically, both diffuse labeling and well defined clusters of rapsynGFP were observed (Fig. 5).

To determine whether the fluorescence clusters in wild-type/ rapsyn-GFP fish and sofa potato/rapsyn-GFP fish corresponded to the sites of synaptic contact, we labeled a small population of motor neurons with Texas Red-dextran by anterograde labeling. In this manner the distribution of rapsyn-GFP and presynaptic terminals could be compared directly for correspondence. We first established that a close correspondence existed between the Texas Red-labeled terminals and the rapsyn-GFP clusters in wild-type/rapsyn-GFP muscle (Fig. 6). Because all neurons were not labeled effectively with Texas Red, some of the rapsyn clusters lacked associated labeled terminals. However, the striking qualitative overlap between labeled terminals and associated rapsynGFP clusters confirmed the idea that rapsyn was located beneath the nerve terminals in wild-type muscle.

These data from wild-type fish contrasted sharply with those from sofa potato/rapsyn-GFP fish. At $5 \mathrm{~d}$ of age most of the nerve terminal endings that were labeled effectively with Texas Reddextran in sofa potato/rapsyn-GFP fish lacked corresponding rapsyn-GFP label in muscle (Fig. 6). This lack of coincidence was most obvious in the middle of the muscle cell where punctate synapses could be identified reliably. Some correspondence was seen between the myosepta labeling by both rapsyn-GFP and Texas Red. However, the coincidence may be a simple result of the fact that the motor neurons run along the myosepta to innervate the muscle; therefore, the overlap may not represent true synaptic contacts. Additionally, myotendinous localizations of $\mathrm{ACh}$ receptors and associated rapsyn localization have been reported in a number of preparations despite the absence of synaptic contacts (Chen et al., 1990). Therefore, we restricted our analyses to the midregion of muscle cells.

To compute the extent of colocalization of terminal and rapsyn labeling, we scored each pixel in individual fields for the presence of either green or red fluorescence (Fig. 7). The detection threshold for scoring a pixel as either red- or green-positive was set to the $50 \%$ intensity level for the overall range in each field. We then quantitated the overlap on the basis of the fraction of red pixels that also scored positive for a green signal (Fig. 7). The converse correlation, being green pixels with or without red signal, was not computed because it would underestimate greatly the extent to which colocalization occurs. In all cases it was impossible to fill all of the motor neurons in the field, leaving some terminals unlabeled. Measurements in eight fields of wild-type/rapsyn-GFP fish indicate a mean coefficient of colocalization corresponding to 0.46 compared with 0.11 for sofa potato/rapsyn-GFP (Fig. 7). These differences are highly significant $(p \ll 0.01$, unpaired Student's $t$ test). Despite the low value for sofa potato/rapsynGFP fish, it appears that infrequent, but authentic colocalization occurs (Fig. 7). The 11\% overlap measured for sofa potato/ rapsyn-GFP is higher than would be predicted by random overlap. On the other hand, the estimated colocalization in wild-type/ GFP rapsyn fish is likely to be an underestimate for two reasons. First, no corrections for differences in emission intensity of Texas Red and GFP were made. Consequently, slight differences in cluster sizes for green and red fluorescence emitters are scored as nonoverlapping. This error is probably small because changing the detection threshold from 50 to $35 \%$ did not alter the coefficient of colocalization significantly. Second, we do not have an additional marker to distinguish between axons and terminal, so some of the red fluorescence is likely to represent tangential images of axons where no rapsyn-GFP signal would be expected. Thus, the sofa potato fish exhibit a greatly impaired ability to localize rapsyn-GFP to subsynaptic terminals compared with wild-type fish.

\section{DISCUSSION}

Relatively few physiological studies have capitalized on the readily available supply of neurologically relevant mutant lines of zebrafish. In particular, the locomotory mutants are especially well tailored for analysis of physiological function as a result of the unparalleled access to both nerve and muscle. Our study offers a systematic approach that can be applied easily to such mutants to establish the precise site of physiological dysfunction. The results of such analyses point to the effectiveness by which specific defects can be identified by the use of physiological analysis alone. In our case we found that the two mutant lines, which exhibited the same behavioral phenotype, resulted from defects in two distinct receptor types in muscle. Perhaps the most important outcome of this study, however, is the demonstration that such mutants can be used to identify new and unexpected functions for even the most well characterized receptor types.

In the mutant line relaxed, synaptic transmission and synaptic morphology appeared completely normal, despite complete muscle paralysis. The lack of contraction in response to depolarization could result from muscle defects in either ryanodine receptors (RyR) or dihydropyridine (DHP) receptors. Our finding that 

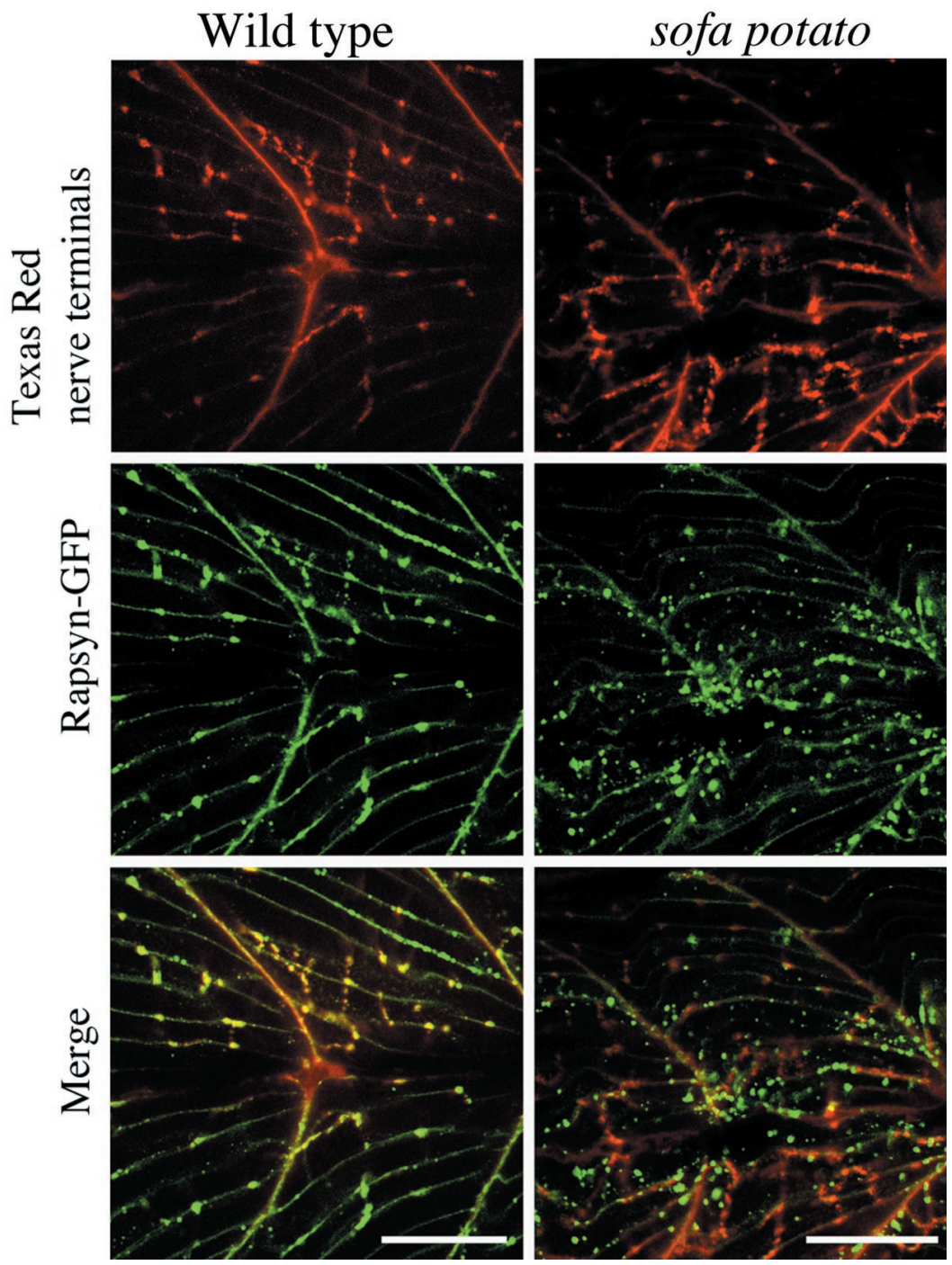

Figure 6. The rapsyn clusters localize beneath nerve terminals in wild-type fish, but not in sofa potato mutant fish. The distribution of nerve terminal endings for wild-type/rapsynGFP (top left) and sofa potato/rapsyn-GFP (top right) lines are shown by red fluorescence. Some, but not all, of the nerve terminals in the field of view were labeled by anterograde filling of the motor neurons with Texas Red-dextran. The distribution of the rapsyn-GFP fusion protein is shown for the same wild-type and sofa potato muscles in the middle panels. The merge is shown in the bottom panels. Scale bars, $50 \mu \mathrm{m}$.

caffeine-induced contracture can be elicited in relaxed indicates that functional ryanodine receptors are present in relaxed mutant fish. Furthermore, measurement of the gating charge movement from myotomal muscle of relaxed points to a specific defect in the DHP receptor, similar to that published for dysgenic mouse mutants (Tanabe et al., 1988; Adams et al., 1990). The charge movements recorded from wild-type zebrafish myotomal muscle compare favorably with those that have been published for mouse skeletal muscle. Additionally, both relaxed mutant zebrafish and dysgenic mouse muscle show considerably reduced charge movement. In a RyR knock-out mouse the ionic conductance through the DHP receptor was reduced, whereas the charge movement remained intact (Nakai et al., 1996), once again pointing to the DHP receptor as the locus of disturbance in relaxed. The DHP receptors in mouse muscle are composed of several subunits, and muscle lacking either $\alpha 1$ or $\beta$ subunits fails to contract and exhibits reduced charge movement (Knudson et al., 1989; Melzer et al., 1995; Gregg et al., 1996). On the other hand, studies to date have indicated only a single DHP receptor subunit in fish (Grabner et al., 1991). If this is the case, then the mutation in relaxed likely resides in the gene coding for the $\alpha 1$ subunit. Confirmation of the locus of the mutation will require analysis of the primary sequence of this gene in wild type and relaxed.

Unlike the case for relaxed, paralysis in sofa potato results from an upstream defect involving neuromuscular transmission. Specifically, evoked and spontaneous synaptic responses are absent in recordings from in vivo muscle, pointing to a postsynaptic origin of the defect. As with relaxed, morphological analyses of GFPfilled motor neurons and associated presynaptic terminals revealed no obvious defects in sofa potato mutant embryos. The inability of sofa potato muscle to respond to applied ACh, along with the absence of labeling by either $\alpha$-Btx or mAb35 antibodies, points to an absence of $\mathrm{ACh}$ receptor $\alpha$ subunits in muscle membrane. In the only other published analysis of a locomotory mutant zebrafish line, nic, paralysis was shown to be a result of a defect in nicotinic receptors. Nic subsequently was shown to represent a splicing defect in the $\alpha$ subunit, thereby inhibiting receptor expression (Sepich et al., 1998). Complementation studies with nic mutant fish have indicated that sofa potato is not a mutation in the gene encoding the $\alpha$ subunit (Granato et al., 1996). Given the lack of available sequence information, it is possible that the point mutation in sofa potato is not located in one of the four additional receptor subunits. However, should the mutation be mapped to one of these receptor subunits, the $\beta$ subunit seems the most viable candidate. Receptors lacking $\gamma, \delta$, or $\epsilon$ subunits can still result in significant levels of expression (Jackson et al., 1990; Kullberg et al., 1990; Liu and Brehm, 1993), 

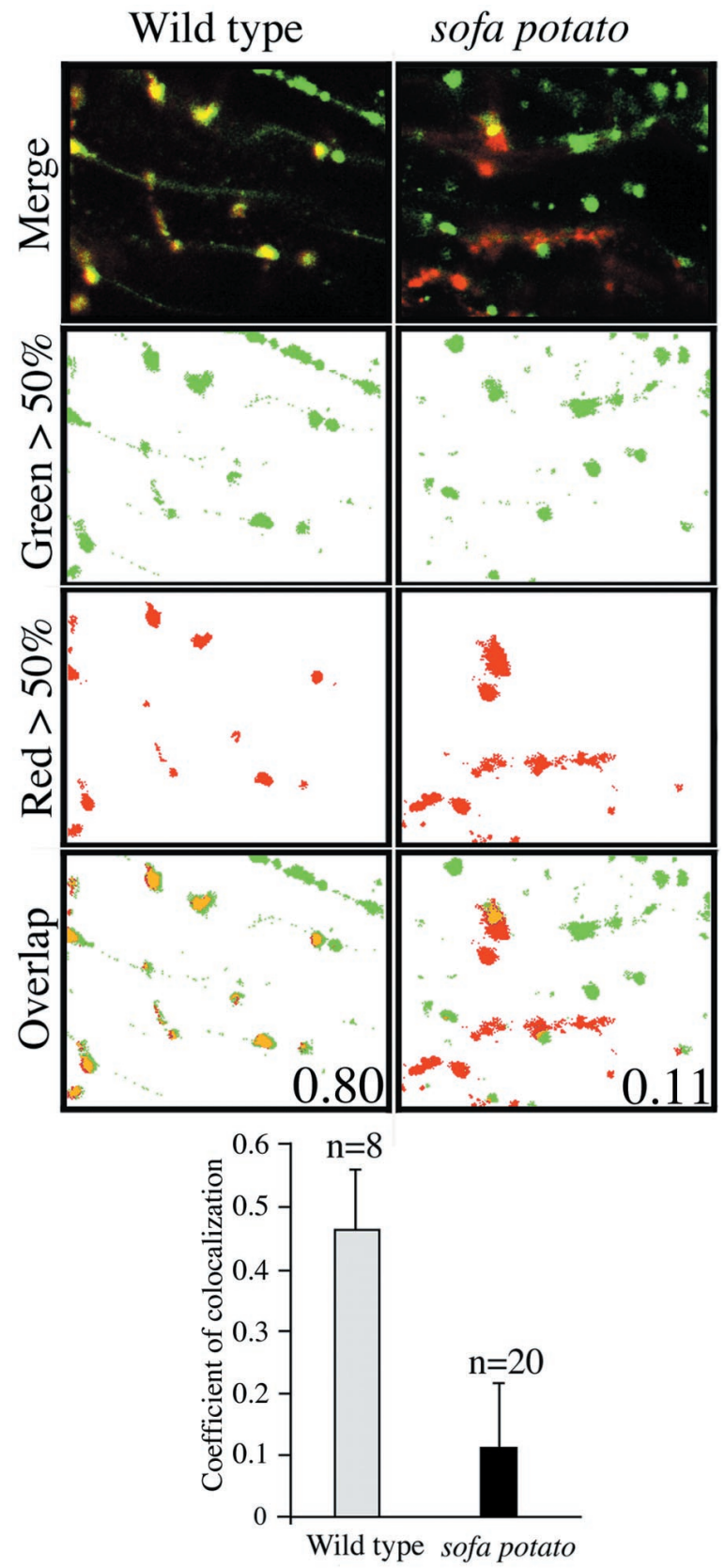

Figure 7. Quantitation of nerve terminal and rapsyn colocalization. The distribution of Texas Red-labeled terminals (red fluorescence) and GFP labeled rapsyn (green fluorescence) are shown for wild-type (left) and sofa potato (right) muscles. In the top panels the merged images of Texas Red and GFP fluorescence distributions with colocalization in yellow are shown. The second and third panels show separate digitally processed images indicating the pixels exceeding the $50 \%$ threshold values for red (Red $>50 \%)$ or green (Green $>50 \%$ ) fluorescence intensities. All pixels falling below the detection threshold of $50 \%$ were converted to values corresponding to white. In the bottom panels (Overlap), the red pixels colocalizing with green pixels are coded orange. The coefficients of colocalization for both wild-type and sofa potato, based on the fractional overlap of red pixels by green pixels, are indicated for the images shown. The mean coefficients for the overall data are indicated in the histogram along with the number of fields that were measured and the SDs.

whereas $\beta$-less receptors exhibit little or no function when they are expressed exogenously.

Analysis of sofa potato neuromuscular synapses revealed unexpected insights into the relationship between the $\mathrm{ACh}$ receptor and the receptor-aggregating subunit rapsyn. Potential sites of interaction have been identified on rapsyn (Ramarao and Cohen, 1998), but the corresponding interaction sites on the ACh receptor have been very elusive. The difficulty in identifying the nature of receptor-rapsyn interactions has greatly hampered understanding of the mechanisms governing receptor clustering. For example, it is clear that rapsyn is required for receptor aggregation, but no studies on muscle have determined conclusively whether the clustering ability of rapsyn requires association with a receptor. In studies on QT6 fibroblast cells clustering by exogenously expressed rapsyn proteins occurred in the absence of ACh receptors (Phillips et al., 1991; Apel et al., 1997), but doubts as to the physiological relevance of this finding have been raised by similar studies on muscle. For example, in cultured myotubes derived from mice deficient in muscle-specific kinase (MuSK), neither rapsyn nor receptor clusters were observed (DeChiara et al., 1996; Zhou et al., 1999). The different findings for these two cell types could be reconciled by the presence of an endogenous MuSK functional homolog in the fibroblast cells (Burden, 1998). Alternatively, clustering in nonmuscle may occur via pathways distinct from those involved in nerve-induced clustering. Such alternative pathways also may underlie the formation of nonsynaptic clusters on muscle in vivo and at focal adhesion zones on muscle in cell culture (Liu and Westerfield, 1992). To resolve such issues requires the analysis of neuromuscular synapses formed in vivo.

Our use of zebrafish has provided the first opportunity for in vivo study of rapsyn clustering. In 5-d-old wild-type fish an excellent correspondence was observed between the distribution of exogenously expressed rapsyn and ACh receptors, consistent with previous reports on endogenous rapsyn distribution in mammalian skeletal muscle (Noakes et al., 1993). This correspondence further validates the use of exogenous rapsyn-GFP for our in vivo study. Unlike the findings from 5-d-old muscle, we observed a lack of correspondence between rapsyn-GFP and receptor in newly developed muscle from 2-d-old fish. In muscle from these young fish the aggregated $\mathrm{ACh}$ receptors were always associated with rapsyn-GFP, but receptorless rapsyn-GFP clusters also were observed. In addition to these findings, we observed frequent rapsyn-GFP clusters in muscle from sofa potato mutants lacking ACh receptors. Thus, the ability of exogenously expressed rapsyn-GFP to self-cluster in wild-type and in mutant sofa potato fish agrees with previous nonmuscle expression systems, including both QT6 and Xenopus oocyte expression systems (Phillips et al., 1991; Apel et al., 1997).

On the basis of these findings, it is tempting to speculate that rapsyn clustering normally precedes association with ACh receptors during development. Although controversial, it has been proposed that association with ACh receptor precedes the formation of rapsyn clusters (Fuhrer et al., 1999; Marchand et al., 2000). We cannot exclude the possibility that, in our case, the lack of close correspondence between rapsyn and $\mathrm{ACh}$ receptor may be exaggerated greatly by the overexpression of rapsyn-GFP. In young fish the actin promoter drives rapsyn-GFP expression to higher levels and earlier in development than likely occurs for endogenous rapsyn (Yoshihara and Hall, 1993). Despite the uncertainty as to the physiological role played by early receptorless rapsyn clusters, our findings support a previous proposal that ACh receptors have the capability to associate postinsertionally with rapsyn (Phillips et al., 1991).

The most unexpected outcome of the analysis of the sofa potato mutant line was the finding that exogenously expressed rapsyn- 
GFP clusters, lacking associated ACh receptors, rarely were localized to the subsynaptic region of muscle. On average, $46 \%$ of the red pixels (nerve terminals) colocalized to green pixels (rapsyn-GFP) in wild-type fish, whereas only $10 \%$ colocalization was observed for sofa potato. The occasional colocalization in sofa potato is not predicted on the basis of random occurrence and suggests that receptorless rapsyn clusters are capable of subsynaptic synaptic recognition, but much more weakly than their receptor-associated rapsyn counterparts. One attractive possibility is that subsynaptic complexes can form, but, without the ACh receptor present for stabilization, the clusters diffuse into the extrasynaptic membrane. In this regard it would be useful to know whether the endogenous rapsyn exhibits a distribution similar to the rapsyn-GFP. However, all of the rapsyn antibodies that were tested failed to cross-react with zebrafish rapsyn (data not shown). Once again, the excellent correspondence seen in wild-type muscle between rapsyn-GFP and terminal staining shows that the inability of rapsyn-GFP clusters to target properly

A

\section{Conventional}

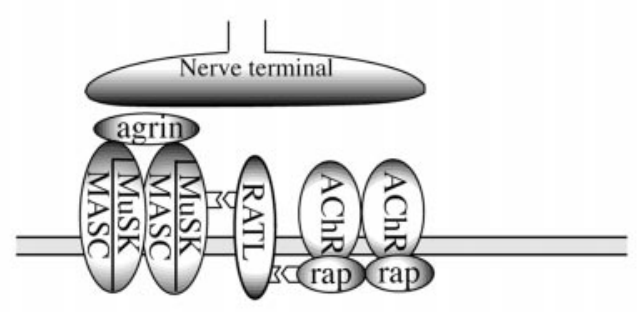

B

Clustering/ sofa potato
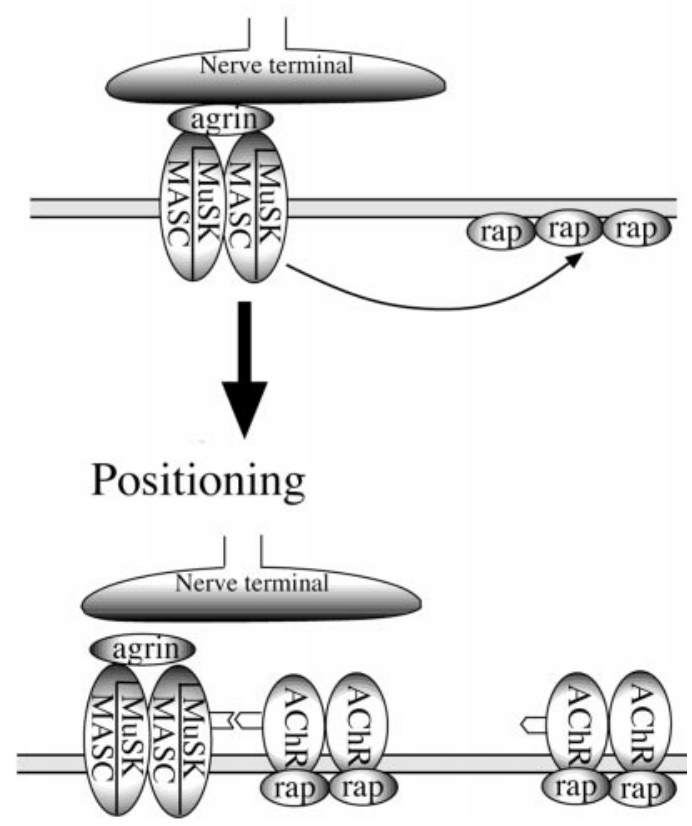

Figure 8. Two models for the clustering and subsynaptic positioning of ACh receptors. In the conventional model $(A)$ the ACh receptor-rapsyn complex is anchored to synaptic MuSK via interactions with a hypothetical RATL. $B$, A model based on our findings wherein clustering and positioning occur as separate processes. The final anchoring of the complex to MuSK occurs via the ACh receptor in this model. in sofa potato was not an artifact of overexpression of a fusion protein. Thus, we conclude that the $\mathrm{ACh}$ receptor is involved somehow in directing the rapsyn cluster to subsynaptic membrane.

Localization of the rapsyn-receptor complex to the synapse is known to require interaction with MuSK (Fig. $8 A$ ), a transmembrane muscle protein that is localized to the synapse by secretion of neuronal agrin (DeChiara et al., 1996; Glass et al., 1996). Hints as to how MuSK signals the rapsyn-receptor complex have been provided by studies on muscle derived from genetically altered knock-out mice and QT6 fibroblasts (Gillespie et al., 1996; Apel et al., 1997; Glass et al., 1997; Zhou et al., 1999). The interaction is thought to involve an extracellular region of MuSK and intracellular rapsyn, requiring the presence of an additional membrane-spanning signaling molecule (RATL) to link MuSK and rapsyn (Fig. 8A; Apel et al., 1997). No candidate for this link has yet been identified via molecular analysis. Our observation that $\mathrm{ACh}$ receptors are necessary for localization raises the possibility that the ACh receptor serves as RATL. Consistent with this idea, the $\mathrm{ACh}$ receptor coimmunoprecipitates MuSK (Fuhrer et al., 1997, 1999). At odds with this idea is the observation that coexpression of MuSK and rapsyn in QT6 cells results in colocalization without the presence of ACh receptors (Apel et al., 1997). However, this result is difficult to reconcile with the conventional model, barring the existence of an endogenous RATL homolog in fibroblasts. As discussed previously, resolution of this problem may require that bona fide in vivo synapses be examined, wherein the nerve-dependent localization can be examined directly. This is possible in zebrafish.

In conclusion, our findings have shed new light on the potential interactions between the ACh receptor and the associated clustering proteins rapsyn and MuSK. The model presented in Figure $8 B$ showing the relationship among these three molecules is speculative in that the sites of interaction between MuSK and $\mathrm{ACh}$ receptor are unknown. However, our findings indicate that developmental acquisition of the high-density ACh receptor subsynaptic aggregates occurs in two distinct steps, an idea proposed by Zhou et al. (1999). First, clustering of receptors occurs as a direct consequence of interactions with rapsyn: molecules, as we demonstrate in this study, that have an intrinsic ability to self cluster. Second, the clusters are localized to the synapse by interactions requiring the receptor rather than by rapsyn alone. Identification of putative genetic defects in sofa potato by physiological analysis now provides a way that the signaling pathways involved in synaptic differentiation can be studied easily in vivo.

\section{REFERENCES}

Adams BA, Tanabe T, Mikami A, Numa S, Beam KG (1990) Intramembrane charge movement restored in dysgenic skeletal muscle by injection of dihydropyridine receptor cDNAs. Nature 346:569-572.

Apel ED, Roberds SL, Campbell KP, Merlie JP (1995) Rapsyn may function as a link between the acetylcholine receptor and the agrinbinding dystrophin-associated glycoprotein complex. Neuron 15:15-26.

Apel ED, Glass DJ, Moscoso LM, Yancopoulos GD, Sanes JR (1997) Rapsyn is required for MuSK signaling and recruits synaptic components to a MuSK-containing scaffold. Neuron 18:623-635.

Burden SJ (1998) The formation of neuromuscular synapses. Genes Dev 12:133-148.

Chen Q, Sealock R, Peng HB (1990) A protein homologous to the Torpedo postsynaptic $58 \mathrm{~K}$ protein is present at the myotendinous junction. J Cell Biol 110:2061-2071.

Currie PD, Ingham PW (1996) Induction of a specific muscle cell type by a hedgehog-like protein in zebrafish. Nature 382:452-455.

DeChiara TM, Bowen DC, Valenzuela DM, Simmons MV, Poueymirou WT, Thomas S, Kinetz E, Compton DL, Rojas E, Park JS, Smith C, DiStefano PS, Glass DJ, Burden SJ, Yancopoulos GD (1996) The 
receptor tyrosine kinase MuSK is required for neuromuscular junction formation in vivo. Cell 85:501-512.

Fetcho JR, O'Malley DM (1995) Visualization of active neural circuitry in the spinal cord of intact zebrafish. J Neurophysiol 73:399-406.

Froehner SC, Luetje CW, Scotland PB, Patrick J (1990) The postsynaptic $43 \mathrm{~K}$ protein clusters muscle nicotinic acetylcholine receptors in Xenopus oocytes. Neuron 5:403-410.

Fuhrer C, Sugiyama JE, Taylor RG, Hall ZW (1997) Association of muscle-specific kinase MuSK with the acetylcholine receptor in mammalian muscle. EMBO J 16:4951-4960.

Fuhrer C, Gautam M, Sugiyama JE, Hall ZW (1999) Roles of rapsyn and agrin in interaction of postsynaptic proteins with acetylcholine receptors. J Neurosci 19:6405-6416.

Gautam M, Noakes PG, Mudd J, Nichol M, Chu GC, Sanes JR, Merlie JP (1995) Failure of postsynaptic specialization to develop at neuromuscular junctions of rapsyn-deficient mice. Nature 377:232-236.

Gillespie SK, Balasubramanian S, Fung ET, Huganir RL (1996) Rapsyn clusters and activates the synapse-specific receptor tyrosine kinase MuSK. Neuron 16:953-962.

Glass DJ, Bowen DC, Stitt TN, Radziejewski C, Bruno J, Ryan TE, Gies DR, Shah S, Mattsson K, Burden SJ, DiStefano PS, Valenzuela DM, DeChiara TM, Yancopoulos GD (1996) Agrin acts via a MuSK receptor complex. Cell 85:513-523.

Glass DJ, Apel ED, Shah S, Bowen DC, DeChiara TM, Stitt TN, Sanes JR, Yancopoulos GD (1997) Kinase domain of the muscle-specific receptor tyrosine kinase (MuSK) is sufficient for phosphorylation but not clustering of acetylcholine receptors: required role for the MuSK ectodomain? Proc Natl Acad Sci USA 94:8848-8853.

Grabner M, Friedrich K, Knaus HG, Striessnig J, Scheffauer F, Staudinger R, Koch WJ, Schwartz A, Glossmann H (1991) Calcium channels from Cyprinus carpio skeletal muscle. Proc Natl Acad Sci USA 88:727-731.

Granato M, van Eeden FJ, Schach U, Trowe T, Brand M, Furutani-Seiki M, Haffter P, Hammerschmidt M, Heisenberg CP, Jiang YJ, Kane DA, Kelsh RN, Mullins MC, Odenthal J, Nüsslein-Volhard C (1996) Genes controlling and mediating locomotion behavior of the zebrafish embryo and larva. Development 123:399-413.

Gregg RG, Messing A, Strube C, Beurg M, Moss R, Behan M, Sukhareva M, Haynes S, Powell JA, Coronado R, Powers PA (1996) Absence of the $\beta$-subunit (cchb1) of the skeletal muscle dihydropyridine receptor alters expression of the $\alpha 1$ subunit and eliminates excitation-contraction coupling. Proc Natl Acad Sci USA 93:13961-13966.

Heidelberger R, Matthews G (1992) Calcium influx and calcium current in single synaptic terminals of goldfish retinal bipolar neurons. J Physiol (Lond) 447:235-256.

Higashijima S, Okamoto H, Ueno N, Hotta Y, Eguchi G (1997) Highfrequency generation of transgenic zebrafish which reliably express GFP in whole muscles or the whole body by using promoters of zebrafish origin. Dev Biol 192:289-929.

Higashijima S, Hotta Y, Okamoto H (2000) Visualization of cranial motor neurons in live transgenic zebrafish expressing green fluorescent protein under the control of the islet-1 promoter/enhancer. J Neurosci 20:206-218.

Huser J, Lipsius SL, Blatter LA (1996) Calcium gradients during excitation-contraction coupling in cat atrial myocytes. J Physiol (Lond) 494:641-651.

Jackson MB, Imoto K, Mishina M, Konno T, Numa S, Sakmann B (1990) Spontaneous and agonist-induced openings of an acetylcholine receptor channel composed of bovine muscle alpha-, beta-, and deltasubunits. Pflügers Arch 417:129-135.

Knudson CM, Chaudhari N, Sharp AH, Powell JA, Beam KG, Campbell KP (1989) Specific absence of the $\alpha 1$ subunit of the dihydropyridine receptor in mice with muscular dysgenesis. J Biol Chem 264:1345-1348.

Kullberg R, Owens JL, Camacho P, Mandel G, Brehm P (1990) Multiple conductance classes of mouse nicotinic acetylcholine receptors expressed in Xenopus oocytes. Proc Natl Acad Sci USA 87:2067-2071.

Lipp P, Huser J, Pott L, Niggli E (1996) Spatially nonuniform $\mathrm{Ca}^{2+}$ signals induced by the reduction of transverse tubules in citrate-loaded guinea-pig ventricular myocytes in culture. J Physiol (Lond) 497:589-597.

Liu DW, Westerfield M (1992) Clustering of muscle acetylcholine receptors requires motoneurons in live embryos, but not in cell culture. J Neurosci 12:1859-1866.

Liu Y, Brehm P (1993) Expression of subunit-omitted mouse nicotinic acetylcholine receptors in Xenopus laevis oocytes. J Physiol (Lond) 470:349-363.

Marchand S, Bignami F, Stetzkowski-Marden F, Cartaud J (2000) The myristoylated protein rapsyn is cotargeted with the nicotinic acetylcholine receptor to the postsynaptic membrane via the exocytic pathway. J Neurosci 20:521-528.

Melzer W, Herrmann-Frank A, Luttgau HC (1995) The role of $\mathrm{Ca}^{2+}$ ions in excitation-contraction coupling of skeletal muscle fibres. Biochim Biophys Acta 1241:59-116.

Nakai J, Dirksen RT, Nguyen HT, Pessah IN, Beam KG, Allen PD (1996) Enhanced dihydropyridine receptor channel activity in the presence of ryanodine receptor. Nature 380:72-75.

Noakes PG, Phillips WD, Hanley TA, Sanes JR, Merlie JP (1993) 43K protein and acetylcholine receptors colocalize during the initial stages of neuromuscular synapse formation in vivo. Dev Biol 155:275-280.

Phillips WD, Kopta C, Blount P, Gardner PD, Steinbach JH, Merlie JP (1991) ACh receptor-rich membrane domains organized in fibroblasts by recombinant 43-kildalton protein. Science 251:568-570.

Ramarao MK, Cohen JB (1998) Mechanism of nicotinic acetylcholine receptor cluster formation by rapsyn. Proc Natl Acad Sci USA 95:4007-4012.

Ribera AB, Nüsslein-Volhard C (1998) Zebrafish touch-insensitive mutants reveal an essential role for the developmental regulation of sodium current. J Neurosci 18:9181-9191.

Saedi MS, Anand R, Conroy WG, Lindstrom J (1990) Determination of amino acids critical to the main immunogenic region of intact acetylcholine receptors by in vitro mutagenesis. FEBS Lett 267:55-59.

Sepich DS, Wegner J, O'Shea S, Westerfield M (1998) An altered intron inhibits synthesis of the acetylcholine receptor $\alpha$-subunit in the paralyzed zebrafish mutant nicl. Genetics 148:361-372.

Tanabe T, Beam KG, Powell JA, Numa S (1988) Restoration of excitation-contraction coupling and slow calcium current in dysgenic muscle by dihydropyridine receptor complementary DNA. Nature 336:134-139.

Westerfield M, Liu DW, Kimmel CB, Walker C (1990) Pathfinding and synapse formation in a zebrafish mutant lacking functional acetylcholine receptors. Neuron 4:867-874.

Yoshihara CM, Hall ZW (1993) Increased expression of the 43-kD protein disrupts acetylcholine receptor clustering in myotubes. J Cell Biol 122:169-179.

Zhou H, Glass DJ, Yancopoulos GD, Sanes JR (1999) Distinct domains of MuSK mediate its abilities to induce and to associate with postsynaptic specializations. J Cell Biol 146:1133-1146. 